\title{
LAURENCE PILON
}




\section{LAURENCE PILON}

\section{Project Description}

Through an approach to painting that is intuitive and speculative, I celebrate a post-humanist understanding of natural phenomena. In this perspective, painting for me is a process of visualizing and imagining complex material qualities in relation with the intention to 'bring to life' sympoietic assemblages in which art-historical, botanical, mineral, and animal forms merge and fragment. Through such a slow process of accretion, strange compositions compress into the space of my paintings to create a synchrony of pictorial fossils. These entanglements serve to disturb our anthropocentric understanding of natural phenomena, proposing instead a post-humanist vision of a world in constant metamorphosis where various temporal, spatial and aesthetic dimensions intersect.

Mythologized spectres are eerie supernatural things, but in our material world of agential entanglements, ghosts are an intrinsic part of the evolution of life. In paleobiology, morphological reappearances are not rare phenomena. Such ghost lineages occur when features of ancient species succeed at re-actualizing themselves, sometimes long after the geological period corresponding to the stratum in which they were found.

Fossil problematica may indicate ghost lineages, but they are more than ghosts. They are unknowable hybrids with characteristics that do not correspond to one specific evolutionary chain, but rather embody unrelated mutative trends.

Similarly, my recent paintings function as phenomena of pictorial fossils in which the ghostly and the monstrous collapse to form problematica. They suggest multi-species entanglements by which the term species takes on a more diffractive meaning that is inclusive of abiotic agencies. 


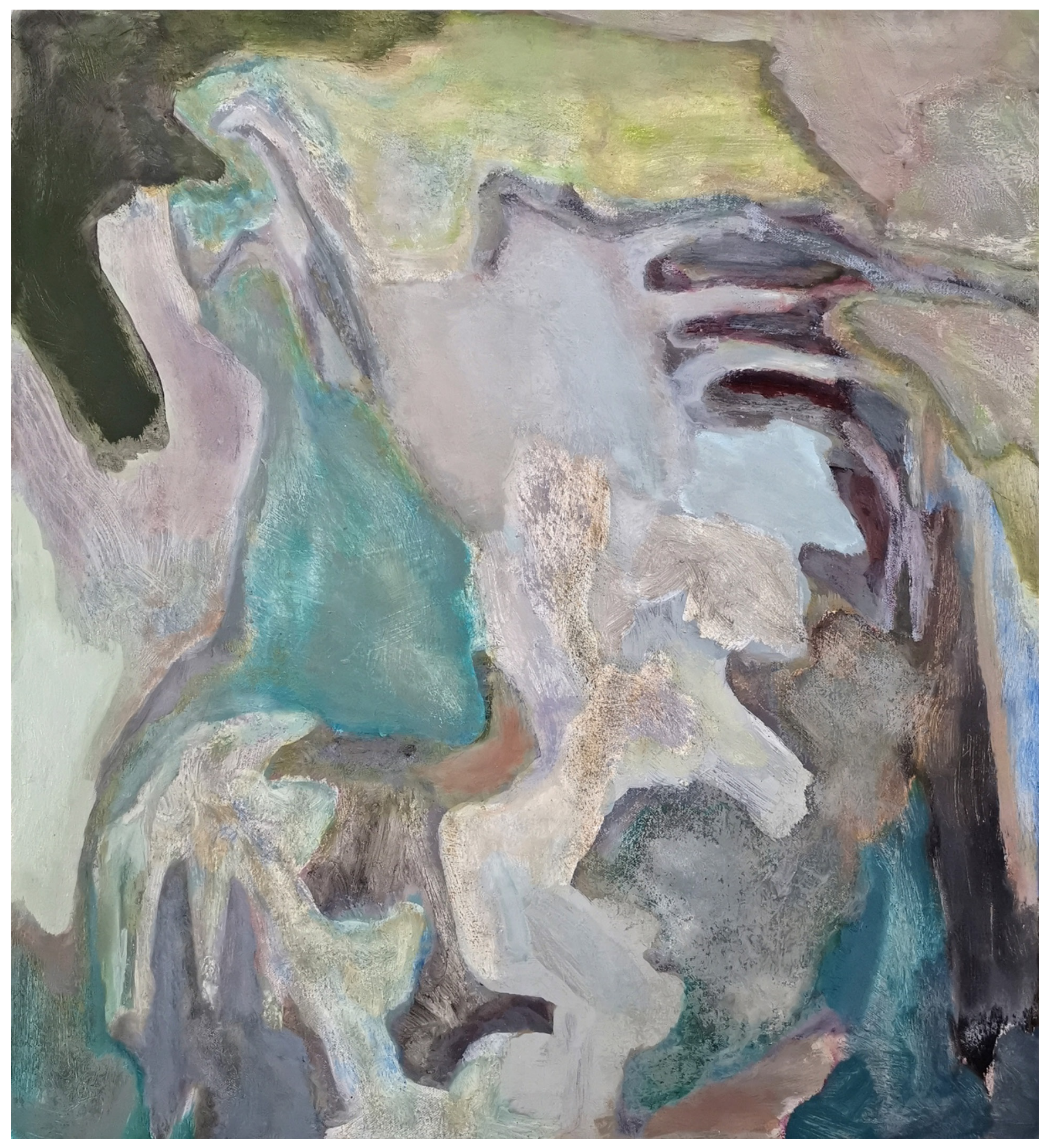

Epibenthic Pulse, oil on canvas over panel, 20 × 22 in, 2020-21. 


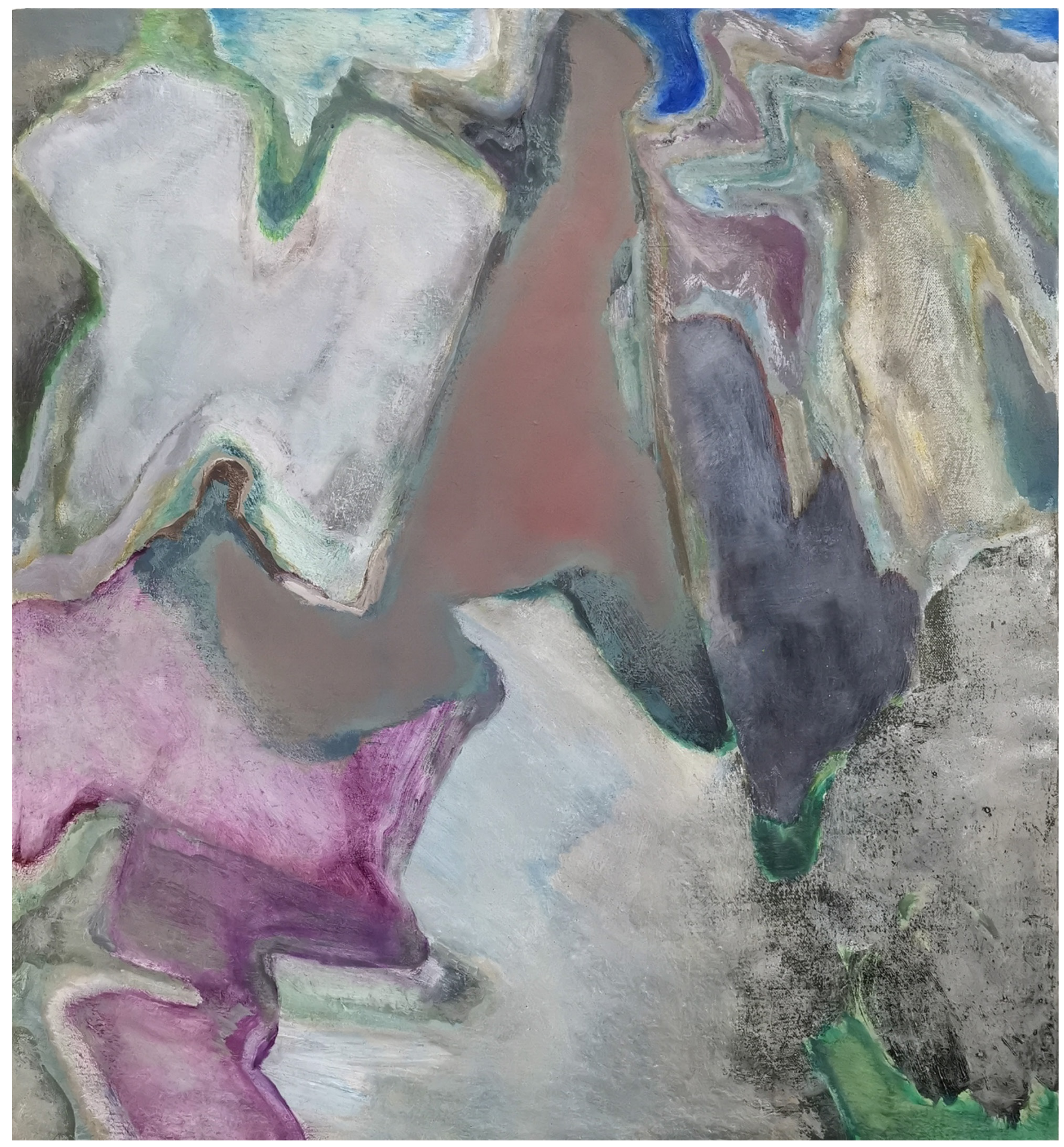

In the Absence of Hands, oil on canvas over panel, $20 \times 22$ in, 2020-2021. 


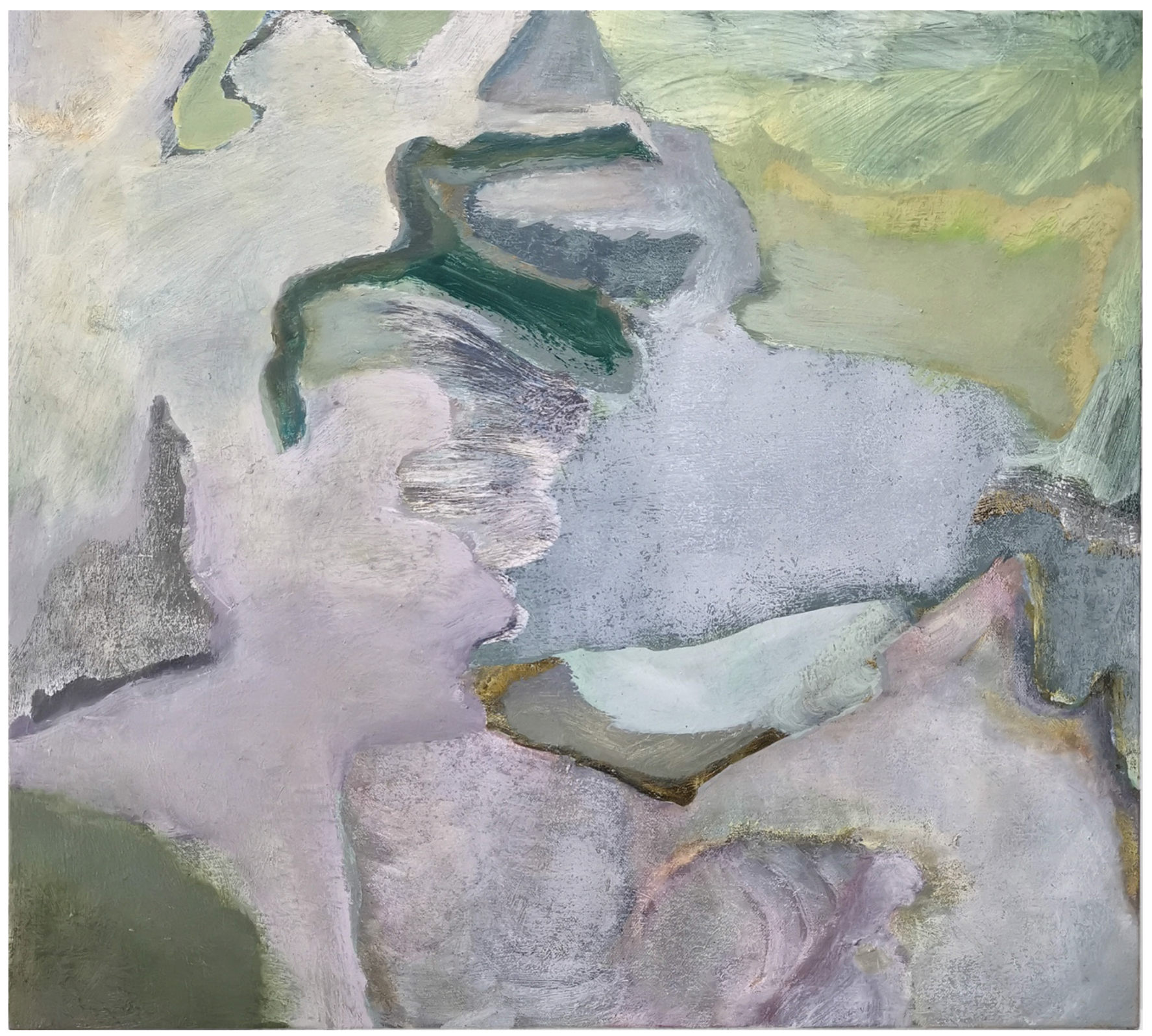

Critter Cluster, oil on canvas over panel, 19 x 17 in, 2020-21. 


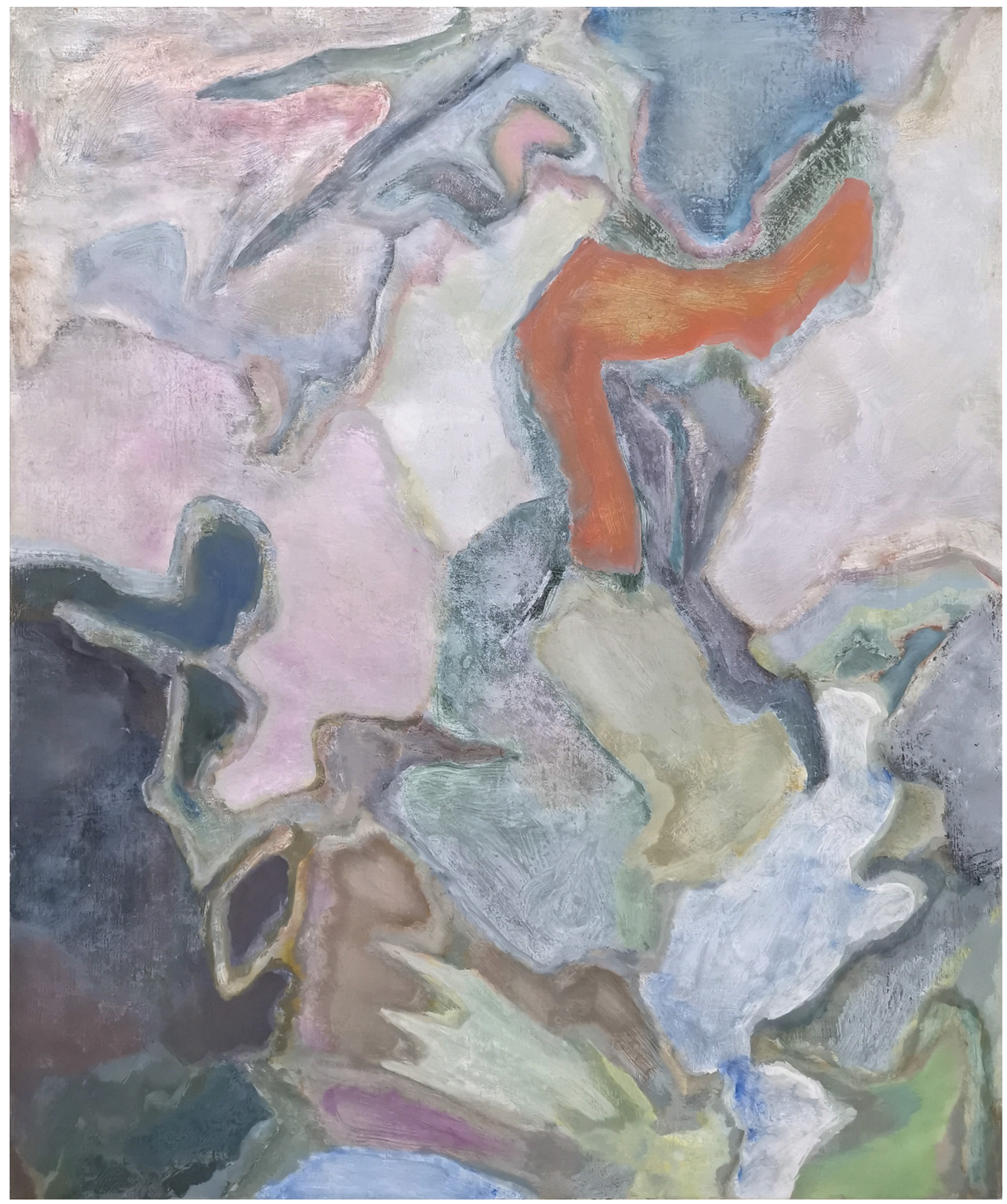

Ichnofabric Tale, oil on canvas over panel, 26 × 31 in, 2020-21. 


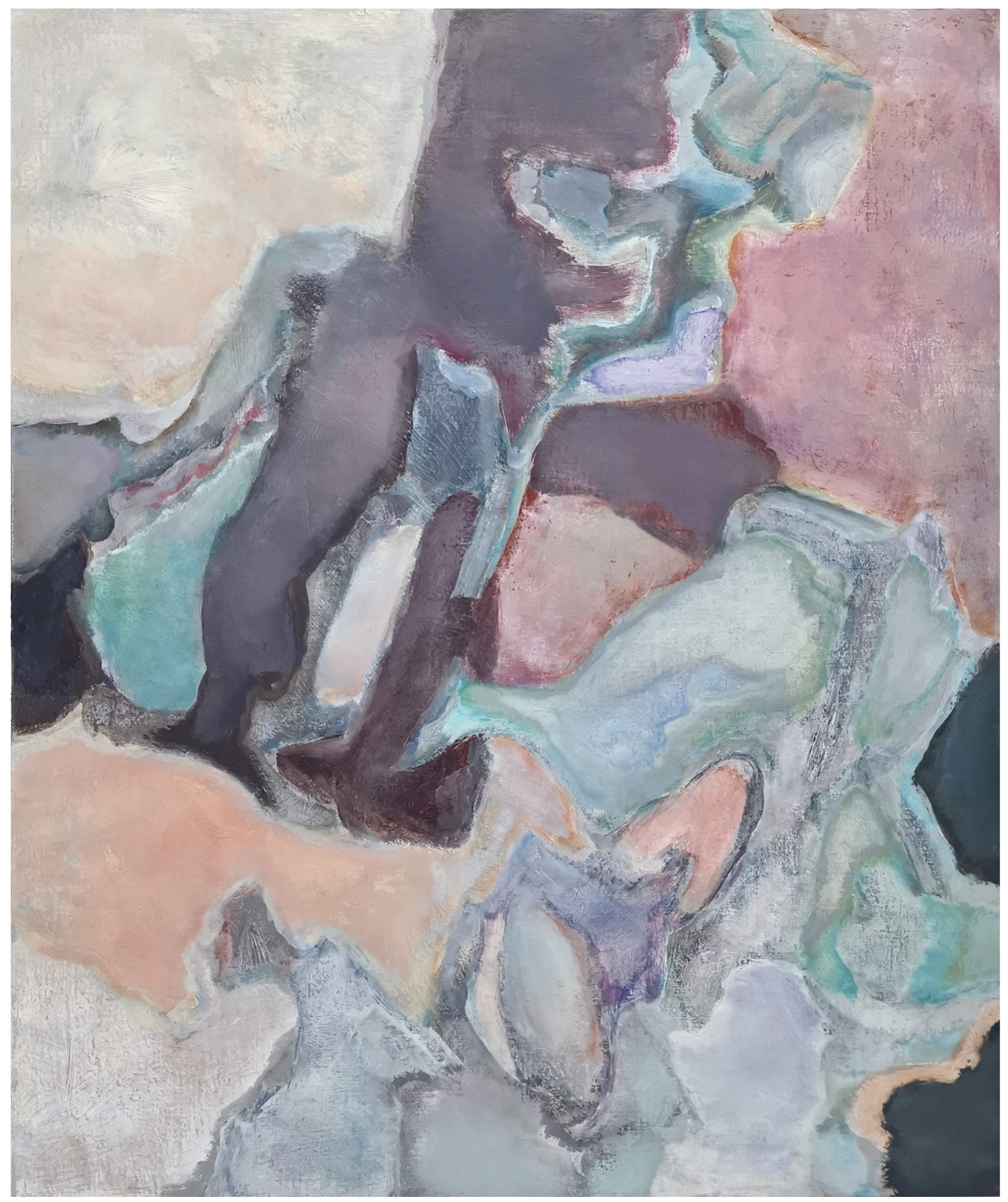

Abiogenesis, oil on canvas over panel, 26 × 31 in, 2020-21. 


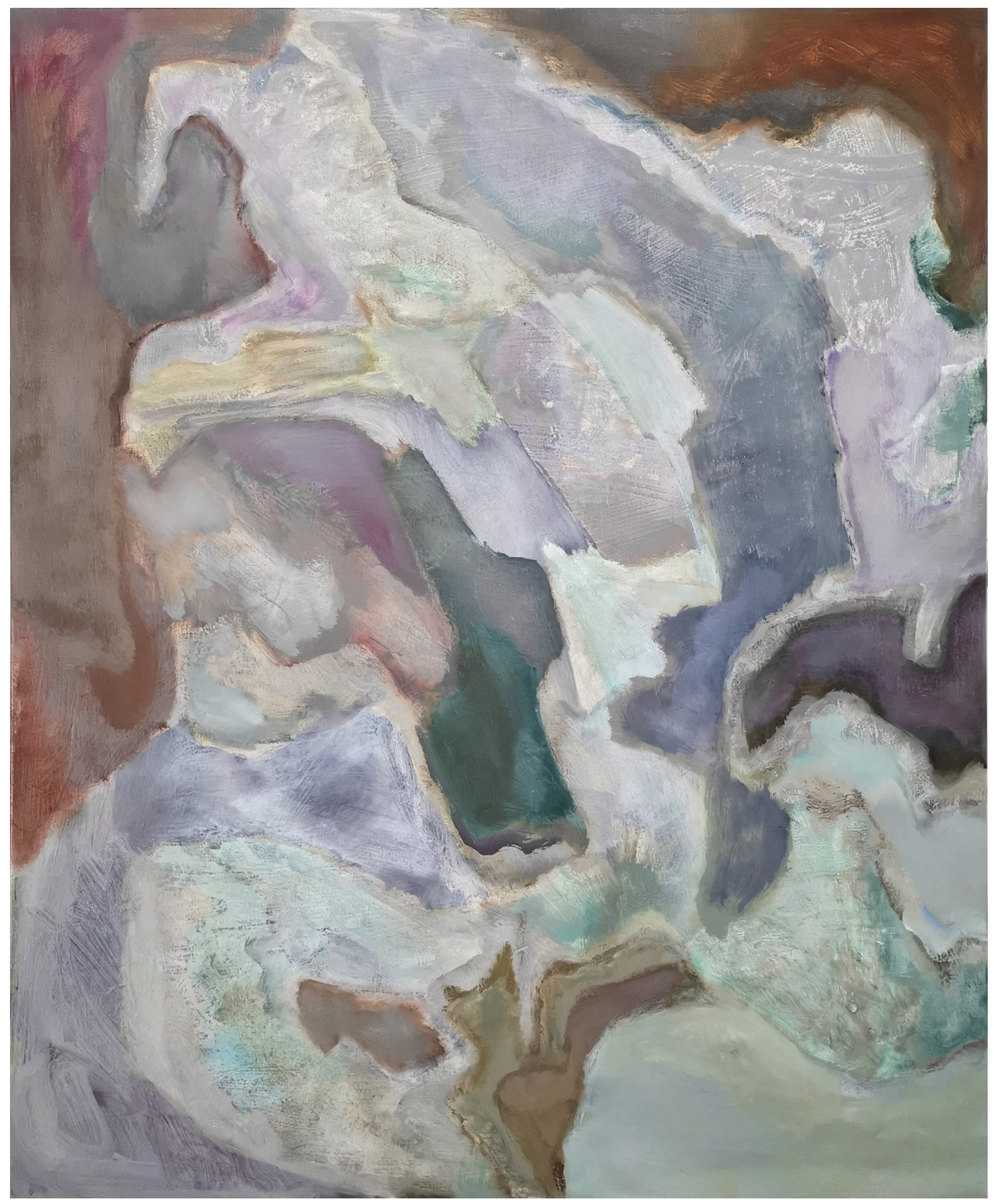

For the Mad Bioturbators, oil on canvas over panel, 33 x 40 in, 2021. 